\title{
A Nested PCR Assay for Detecting Valsa mali var. mali in Different Tissues of Apple Trees
}

Rui Zang, State Key Laboratory of Crop Stress Biology for Arid Areas and College of Plant Protection, Zhiyuan Yin, State Key Laboratory of Crop Stress Biology for Arid Areas and Innovative Experimental College, and Xiwang Ke, Xiaojie Wang, Zhengli Li, Zhensheng Kang, and Lili Huang, State Key Laboratory of Crop Stress Biology for Arid Areas and College of Plant Protection, and Northwest A\&F University, Yangling 712100, China

\begin{abstract}
Zang, R., Yin, Z., Ke, X., Wang, X., Li, Z., Kang, Z., and Huang, L. 2012. A nested PCR assay for detecting Valsa mali var. mali in different tissues of apple trees. Plant Dis. 96:1645-1652.

A nested polymerase chain reaction (PCR) assay for detecting Valsa mali var. mali, the causal agent of apple tree Valsa canker, was developed. One pair of genus-specific primers was designed based on the ribosomal DNA internal transcribed spacer conservative sequence of the Valsa genus and one pair of species-specific primers was designed based on the specific sequence of $V$. mali var. mali. The specificity of the genus-specific and species-specific primers was evaluated against $10 \mathrm{~V}$. mali var. mali isolates, $10 \mathrm{~V}$. mali var. pyri isolates, 4 isolates from closely related Valsa spp., and 8 isolates from fungal species that are commonly isolated from naturally infected apple bark tissue. A distinct band of $348 \mathrm{bp}$ in length was detected in all V. mali var. mali isolates but not in other tested species and the V. mali var. pyri variety. The sensitivity of this assay was evaluated by serial dilutions of DNA extracted from $V$. mali var. mali pure cultures and apple bark tissues with or without visible symptoms. The results showed that the assay was able to detect as little as $100 \mathrm{fg}$ of DNA in mycelial samples and apple bark tissues with visible symptoms, whereas the lowest detecta-

ble concentration was $10 \mathrm{pg}$ of DNA in symptomless apple bark tissues. The efficiency of the nested PCR assay was compared with that of fungal isolation assays. All symptomless and symptomatic samples from which the pathogen was successfully isolated yielded a PCR product of the expected size. The detection rate of nested PCR for symptomless samples was $64.7 \%$, which was much higher than the detection rate of $20.6 \%$ by fungal isolation. The PCR analysis of different symptomless tissues showed that the incidence of $V$. mali var. mali was different in different tissues of apple trees. The average incidence of $V$. mali var. mali was $89 \%$ in terminal buds, $71 \%$ in internodes, and $48 \%$ in bud scale scars. Moreover, the incidence of $V$. mali var. mali in nonsymptomatic tissues was higher in orchards where more trees were infected. Taken together, the assay developed in this study can be used for rapid and reliable detection of $V$. mali var. mali in tissues of apple trees with or without symptoms and also for monitoring the presence of the pathogen at an early stage of disease development.
\end{abstract}

Valsa canker, caused by Valsa mali Miyabe \& Yamada, is one of the most destructive stem diseases of apple trees (Malus spp.) in China $(4,18,19)$, Japan (1), and Korea (15) and causes serious yield losses in apple-producing regions, especially in Shaanxi province $(16,21)$. An investigation in 2003 and 2004 in Shaanxi province showed, on average, $30 \%$ diseased trees; whereas, in some orchards, the incidence of diseased trees was over $90 \%$ (16). Because little is known about the genetic characteristics of the pathogen, an effective disease control strategy was not established for a long time. Recently, it was reported that significant intraspecific genetic differentiation exists in $V$. mali; two varieties, $V$. mali var. mali and V. mali var. pyri, were recognized (18). V. mali var. mali just infects apple, whereas $V$. mali var. pyri can occur on both apple and pear. However, the two varieties have different pathogenicity on apple. $V$. mali var. mali was significantly more aggressive on apple than $V$. mali var. pyri (18).

The disease is characterized by cankers on trunks, twigs, and scaffold limbs (14). Cankers are sunken, swollen, distorted, and cracked areas of bark that may be dotted with red pustules. A large number of black pycnidia appear on the surface of cankers (13). Importantly, the infection always leads to expanding cankers, resulting in the death of twigs, branches, trunks, and eventually the entire tree (1). Entire orchards destroyed by this disease are prevalent in many apple-producing regions in China $(19,21)$.

Corresponding author: L. Huang, E-mail: huanglili1 @ hotmail.com

Accepted for publication 24 May 2012.

http://dx.doi.org/10.1094/PDIS-05-11-0387-RE

(C) 2012 The American Phytopathological Society
The pathogen infects trees through damage or injury to the bark, such as fresh pruning wounds, fruit scars, and freeze injury (13). The typical symptoms are easy to observe in winter and spring. The fruiting bodies and spores are readily found in spring. Cytospora spp., the anamorphs of Valsa spp., have been considered facultative wound parasites of many broadleaf tree species (2). Christensen et al. (5) suggested that Cytospora spp. might cause symptomless infection as a latent pathogen. In most cases, the latent period will last until the host becomes stressed. However, it remains unknown whether the asymptomatic sound bark and other tissues of apple trees carry the causal fungi or not.

It is very important to address this critical issue in order to obtain more complete knowledge of the latent infection and disease cycle, and implement an effective strategy for controlling this disease. There are two methods that can be used to detect this pathogen in apple tree tissue: either by direct isolation of the pathogen or by molecular detection techniques. However, the isolation of Valsa spp. in newly infected tissues as well as latent infection of apparently healthy tissue by conventional methods is difficult and time consuming.

With the development of molecular techniques based on DNA analysis, the polymerase chain reaction (PCR) method has become one of the most effective and dependable methods for detection, identification, and classification of plant-pathogenic fungi (10). The internal transcribed spacer (ITS) regions of ribosomal DNA (rDNA) genes are ideal candidates for designing species-specific primers because they are conserved within the same species but variable between different species. Furthermore, the rDNA gene sequence appears in multiple copies in the genome, resulting in more efficient PCR amplification and, thereby, a higher sensitivity for detection (6). The species-specific primers based on the rDNAITS sequence in the PCR have been frequently applied to detection and identification of many different pathogens in plants $(6,11,12)$. 
However, because PCR inhibitors, such as phenolic compounds, are often present in woody plant tissues, conventional one-step PCR techniques are not suitable to identify and detect pathogens in these crops. Thus, a more sensitive PCR assay is needed. The nested PCR appears to be a logical choice because of its increased sensitivity and specificity of detection (17). This assay has been successfully applied for detection of fungal pathogens in woody plants. Eutypa lata and Eutypella vitis were specifically detected in grapevine as well as latent infections by Sphaeropsis sapinea in Austrian pine tissue $(3,6)$. In light of these results, the nested PCR assay has a potential to be routinely used for detecting pathogens in plant tissues.

The objectives of this study were to (i) develop a reliable and sensitive PCR-based method for detecting and identifying $V$. mali var. mali in symptomatic and symptomless infected apple tissues and (ii) determine the distribution of this pathogen in different apple tree tissues.

\section{Materials and Methods}

Fungal isolation. V. mali var. mali isolates used in this study were partly provided by the Integrated Plant Diseases Management Laboratory in the College of Plant Protection, Northwest A\&F University, and some isolates were obtained from infected apple tree bark of limbs from different orchards in Shaanxi province. The infected twigs with visible canker symptoms were collected in plastic bags and, upon arrival in the laboratory, were washed with tap water and air dried at room temperature. Between the symptomless and apparently infected area, samples were taken and cut into small pieces, which were soaked into $70 \%$ ethanol for 2 to 3 $\min$. Then, the pieces were washed twice with sterile water to remove the ethanol from the surface of the samples and transferred with sterile forceps onto potato dextrose agar (PDA) in petri dishes. The plates were incubated at $25^{\circ} \mathrm{C}$ for 3 days, and mycelial plugs were cut with a cork borer from the margins of the colonies and transferred to water agar plates. After incubation at $25^{\circ} \mathrm{C}$ for 5 days, single hyphal tips were cut with a sterile scalpel under the microscope and transferred to PDA to obtain a single hyphal colony. Stock cultures of all single hyphal isolates were stored in $15 \%$ glycerol at $-80^{\circ} \mathrm{C}$.

DNA extraction from the single hyphae cultures. For DNA extraction, the stock cultures were transferred onto PDA plates and incubated at $25^{\circ} \mathrm{C}$ for 3 days in the dark and, from the edge of the colony, five small plugs ( $5 \mathrm{~mm}$ in diameter) were transferred into $25 \mathrm{ml}$ of potato dextrose broth in $250-\mathrm{ml}$ flasks. The cultures were incubated as still culture at $25^{\circ} \mathrm{C}$ for 5 days. The mycelium was filtered through sterile gauze and approximately $250 \mathrm{mg}$ of fresh mycelium was collected into 2.0-ml microcentrifuge tubes and then lyophilized for DNA extraction. The procedure for DNA extraction followed that described by Lee et al. (7), with slight modifications. The lyophilized mycelium was ground to a fine powder in a mortar and pestle, and then the powder was suspended in $800 \mu \mathrm{l}$ of lysis buffer $(50 \mathrm{mM}$ ethylene diamine tetraacetic acid [EDTA], $100 \mathrm{mM}$ Tris- $\mathrm{HCl}$ [pH 8.0], and 3\% sodium dodecyl sulfate [SDS]), followed by brief vortexing and then incubation at $65^{\circ} \mathrm{C}$ for $1.5 \mathrm{~h}$. Subsequently, $800 \mu \mathrm{l}$ of phenol/chloroform/isoamyl alcohol (25:24:1) was added to the mixture. The tubes were gently inverted several times and centrifuged at room temperature for 15 $\min$ at $12,000 \mathrm{rpm}$. The aqueous phase was transferred to a $1.5-\mathrm{ml}$ tube and an equal volume of chloroform was added to the tube. The mixture was centrifuged again at the same speed, the top aqueous layer was transferred into a $1.5-\mathrm{ml}$ tube, and $10 \mu \mathrm{l}$ of $3 \mathrm{M}$ sodium acetate and $200 \mu \mathrm{l}$ of isopropanol were added. After inverting the tubes several times, threads of precipitated DNA were observed. The suspension was centrifuged at $12,000 \mathrm{rpm}$ for $10 \mathrm{~min}$, the supernatant was poured off carefully, and the DNA pellet was rinsed twice with $100 \mu \mathrm{l}$ of $70 \%$ ice-cold ethanol. When the ethanol had almost evaporated, the pellet was suspended in $50 \mu \mathrm{l}$ of Tris-EDTA buffer (10 mM Tris-HCl and $1 \mathrm{mM}$ EDTA, $\mathrm{pH}$ 8.0) overnight at $4^{\circ} \mathrm{C}$. Afterward, $1.0 \mu \mathrm{l}$ of RNase at $10 \mathrm{mg} / \mathrm{ml}$ (SigmaAldrich) was added to digest RNA in the DNA suspension, which was incubated at $37^{\circ} \mathrm{C}$ for $2 \mathrm{~h}$. After evaluation of the quality of DNA by an ND-1000 spectrophotometer (NanoDrop Technologies, Inc.), the DNA was stored at $-20^{\circ} \mathrm{C}$.

Collection of symptomatic and symptomless tissue samples. In order to know the relationship between the diseased tree incidence and V. mali var. mali incidence in symptomless tissue in apple orchards, the symptomless samples used for detection of $V$. mali var. mali were collected from six orchards in Yangling, Shaanxi province. The incidence of diseased trees in each orchard was calculated by evaluation of 25 trees. In each orchard, five trees with typical symptoms were then randomly selected and four 1year-old symptomless twigs in four directions were cut from each tree. All samples originating from the same orchard were collected in a plastic bag. The samples were washed with tap water and air dried in the laboratory. The terminal buds and bud scale scars of each twig were collected separately. The internode tissues of each twig were selected randomly. Twigs showing visible pycnidia or water-soaked cankers were also collected. Then, the buds and bark and canker tissues were cut into small pieces and placed in an autoclaved mortar. Liquid nitrogen and quartz sand were added and the samples were ground to a fine powder with a pestle. The powder was transferred into a $2.0-\mathrm{ml}$ microcentrifuge tube and used for DNA extraction.

Fungal DNA extraction from symptomless apple tissues. The fungal DNA from symptomless apple twigs was extracted as described by Zhang et al. (22), with slight modifications. The powder samples were suspended in $800 \mu \mathrm{l}$ of extraction buffer, containing $2 \%(\mathrm{wt} / \mathrm{vol})$ cetyltrimethylammonium bromide (CTAB), polyvinyl pyrrolidone (PVP), $\beta$-mercaptoethanol, $1.4 \mathrm{M} \mathrm{NaCl}, 20 \mathrm{mM}$ EDTA $(\mathrm{pH} 8.0)$, and $100 \mathrm{mM}$ Tris- $\mathrm{HCl}\left(\mathrm{pH} \mathrm{8.0)}\right.$, and incubated at $65^{\circ} \mathrm{C}$ for $2 \mathrm{~h}$ followed with gentle shaking every $10 \mathrm{~min}$. Then, an equal volume $(800 \mu \mathrm{l})$ of phenol/chloroform/isoamyl alcohol $(25: 24: 1)$ was added to each tube. The tubes were inverted several times and centrifuged at $12,000 \mathrm{rpm}$ for $10 \mathrm{~min}$. The supernatant $(500 \mu \mathrm{l})$ was transferred to a $1.5-\mathrm{ml}$ tube and eluted with an equal volume of chloroform. After centrifugation (at 12,000 rpm for $10 \mathrm{~min}$ ), the aqueous phase $(350 \mu \mathrm{l})$ was collected and DNA was precipitated by addition of $60 \mu \mathrm{l}$ of $3 \mathrm{M}$ sodium acetate and a two-thirds volume of isopropanol followed by incubation at $-20^{\circ} \mathrm{C}$ overnight. The following procedure is the same as the extraction of DNA from mycelium described above.

ITS amplification, sequencing, and primer design. The ITS region of the pathogen was amplified by the universal primers designated as ITS1 (5'-TCC GTA GGT GAA CCT GCG-3') and ITS4 (5'-TCC TCC GCT TAT TGA TAT-3') to assess the suitability of the DNA isolated for amplification (20). The PCR assay conditions were the same as those described by Wang et al. (18). The PCR products were sequenced along both strands with ITS1 and ITS4 primers using an Applied Biosystems Sequencer 3130XL (Applied Biosystems). The ITS sequences for different Valsa spp., including $V$. malicola Z. Urb (DQ243802), V. persoonii Nitschke (DQ996042), V. sordida Nitschke (EF101159), V. ambiens (Pers.) Fr. (AY347339), and V. salicina (Pers.) Fr. (EF447417), were publicly available on the National Center for Biotechnology Information website. These sequences were analyzed using EditSeq and SeqMan in the DNASTAR software (DNASTAR, Inc.). The conserved ITS sequences within the genus Valsa were used to design the first pair of primers by the software Primer Premier 5.0 package (Premier Biosoft International), which was used for the first round of nested PCR amplification to enrich the amount of fungal DNA present in the sample. The species-specific primers were designed using the software Primer Premier 5.0 package according to the idiosyncratic ITS sequences of the $V$. mali var. mali isolates SXYL29 (JN575597), GSZL86 (JN412603), and NXLW92 (JN412604). The species-specific primers were preliminarily evaluated for their specificity using the Primer-Blast program in the GenBank.

Specificity of the primers. The specificity of the primers was evaluated using closely related Valsa spp. such as V. malicola, $V$. sordida, V. persoonii, and a Valsa sp. Also some distantly related 
species isolated from infected apple tissues such as Fusarium spp., Alternaria spp., and Penicillium digitatum (Pers.) Sacc., and a Puccinia striiformis f. sp. tritici isolate representing a pathogen from a herbaceous plant, were also included for this purpose. Finally, some pathogens causing similar canker diseases on apple twigs were included as well (Table 1). In addition, five $V$. mali var. pyri isolates isolated from apple and five V. mali var. pyri isolates isolated from pear were also used to test the specificity of the primers.

The nested PCR was performed using a DNA thermal cycler PTC-200 (Bio-Rad) under the following conditions for the first run of PCR reactions $(25.0 \mu \mathrm{l}): 1 \times$ PCR buffer $(75 \mathrm{mM}$ Tris- $\mathrm{HCl}$ [pH 8.8], $20 \mathrm{mM}\left[\mathrm{NH}_{4}\right]_{2} \mathrm{SO}_{4}$, and $0.01 \%$ Tween 20$), 2.5 \mathrm{mM}$ $\mathrm{MgCl}_{2}, 0.1 \mathrm{mM}$ dNTP mixture, $0.4 \mu \mathrm{M}$ genus-specific primer Valsa forward (VF) and Valsa reverse (VR), 1.25 unit of Taq DNA polymerase (Fermentas), and approximately $10 \mathrm{ng}$ of total DNA. The amplification reactions were carried out under the following conditions: $94^{\circ} \mathrm{C}$ for $4 \mathrm{~min}$; followed by 40 cycles of $94^{\circ} \mathrm{C}$ for $30 \mathrm{~s}, 64.7^{\circ} \mathrm{C}$ for $30 \mathrm{~s}$, and $72^{\circ} \mathrm{C}$ for $1 \mathrm{~min}$; and ending with a final extension at $72^{\circ} \mathrm{C}$ for $10 \mathrm{~min}$. The reactions lacking template DNA served as a negative control and the known $V$. mali var. mali species isolate \$XYC46 were used as a positive control (Table 1).

For the second round of amplification, the reaction mixtures $(25.0 \mu \mathrm{l})$ contained $1 \times$ PCR buffer $(75 \mathrm{mM}$ Tris-HCl [pH 8.8], 20 $\mathrm{mM}\left[\mathrm{NH}_{4}\right]_{2} \mathrm{SO}_{4}$, and $0.01 \%$ Tween 20 ), $2.5 \mathrm{mM} \mathrm{MgCl} 2,0.1 \mathrm{mM}$ dNTP mixture, $0.4 \mu \mathrm{M}$ species-specific primer $V$. mali var. mali forward $(\mathrm{VmF})$ and $V$. mali var. mali reverse $(\mathrm{VmR}), 1.25$ unit of Taq DNA polymerase (Fermentas), and $1.0 \mu \mathrm{l}$ of the first-run PCR amplification product as a template. The following PCR amplification conditions were employed: initial denaturation step of 4 min at $94^{\circ} \mathrm{C}$; followed by 35 cycles of $30 \mathrm{~s}$ at $94^{\circ} \mathrm{C}, 45 \mathrm{~s}$ at $64.3^{\circ} \mathrm{C}$, and 1 min at $72^{\circ} \mathrm{C}$; and ending with a final extension of 10 min at $72^{\circ} \mathrm{C}$. Finally, the PCR products were rapidly cooled to $4^{\circ} \mathrm{C}$.
The PCR products were separated on $1.5 \%$ agarose gel stained with ethidium bromide in Tris-acetate buffer and photographed with a Molecular Imager gel imaging system (Bio-Rad).

Sensitivity of the assay. To test sensitivity of the nested PCR assay, DNA extracts from V. mali var. mali isolate 03-8-1 mycelium and apple tree bark tissues with or without visible symptoms were used as templates for the first run of PCR under the conditions described above. The DNA extracts from fungal mycelium and apple bark tissues showing visible symptoms were diluted to 400 , 40, 4, and $1 \mathrm{ng} / \mu \mathrm{l} ; 100,10$, and $1 \mathrm{pg} / \mu \mathrm{l}$; and 100,10 , and $1 \mathrm{fg} / \mu \mathrm{l}$ for use as templates. The DNA extracts from apple bark tissues without visible symptoms were diluted to $300,30,3$, and $1 \mathrm{ng} / \mu \mathrm{l} ; 100$, 10 , and $1 \mathrm{pg} / \mu \mathrm{l}$; and 100,10 , and $1 \mathrm{fg} / \mu \mathrm{l}$. The second PCR amplification using species-specific primers $\mathrm{VmF}$ and $\mathrm{VmR}$ was conducted using the parameters as described above.

Nested PCR detection of $V$. mali var. mali on artificially inoculated apple twigs. One isolate of $V$. mali var. mali from Shaanxi province (03-8-1) was used to inoculate healthy symptomless, 2year-old 'Fuji' apple twigs. The isolates were cultured on PDA for 3 days prior to inoculation. The twigs were washed in tap water and cut into short sections (about $45 \mathrm{~cm}$ long), dipped into $70 \%$ ethanol for $3 \mathrm{~min}$, washed in sterile water twice, and air dried. In total, 10 twigs were used for inoculation. The cut twigs were sealed with hot paraffin wax at the morphological upper end, and the burn wounds were made with a nail head ( $8 \mathrm{~mm}$ in diameter) which was heated in the flame of alcohol lamp. There were three inoculated sites on each twig. A plug of agar with mycelium was affixed on the wound and sealed with Parafilm M (Parafilm). The twigs were planted in wet sand in $20-\mathrm{cm}$-diameter pots. The negative control consisted of a twig inoculated with a sterile plug of PDA. Following 20 days of growth in a greenhouse, the diseased tissue around the inoculation sites (approximately $1.5 \mathrm{~cm}$ long) was removed for DNA extraction, and the nested PCR assay was performed as described previously.

Table 1. Isolates of Valsa mali var. mali, V. mali var. pyri, and other fungal species used for determining the specificity of species-specific primers in the nested polymerase chain reaction amplification

\begin{tabular}{|c|c|c|c|c|c|}
\hline Species & Isolate number & Host & Location & Year & GenBank number \\
\hline V. mali var. mali & SXMX02 & Malus domestica Borkh. & Meixian, Shaanxi & 2003 & JN412598 \\
\hline$V$. mali var. mali & $03-3-1$ & M. domestica & Qianyan, Shaanxi & 2003 & JN418997 \\
\hline V. mali var. mali & $03-8-1$ & M. domestica & Qianxian, Shaanxi & 2003 & JN412599 \\
\hline V. mali var. mali & HBBD10 & M. domestica & Baoding, Hebei & 2003 & JN412606 \\
\hline V. mali var. mali & SXYL29 & M. domestica & Yangling, Shaanxi & 2003 & JN575597 \\
\hline V. mali var. mali & SXFF43 & M. domestica & Fufeng, Shaanxi & 2003 & JN412600 \\
\hline V. mali var. mali & \$XYC46 & M. domestica & Yuncheng, Shanxi & 2003 & JN412601 \\
\hline V. mali var. mali & HNXX47 & M. domestica & Xinxiang, Henan & 2003 & JN412607 \\
\hline V. mali var. mali & SXPC69 & M. domestica & Pucheng, Shaanxi & 2003 & JN412602 \\
\hline V. mali var. mali & GSLZ86 & M. domestica & Lanzhou, Gansu & 2005 & JN412603 \\
\hline V. mali var. mali & NXLW92 & M. domestica & LingWu, Ningxia & 2005 & JN412604 \\
\hline V. mali var. mali & SDQX118 & M. domestica & Qixia, Shandong & 2005 & JN412605 \\
\hline V. mali var. pyri & $03-14-1$ & M. domestica & Yangling, Shaanxi & 2003 & JN673554 \\
\hline V. mali var. pyri & SXYL126 & M. domestica & Yangling, Shaanxi & 2005 & JN662365 \\
\hline V. mali var. pyri & SXYL134 & M. domestica & Yangling, Shaanxi & 2005 & JN662366 \\
\hline$V$. mali var. pyri & SXYL135 & M. domestica & Yangling, Shaanxi & 2005 & JN662367 \\
\hline V. mali var. pyri & GSZY113 & M. pumila & Zhangye, Gansu & 2005 & GU174589 \\
\hline$V$. mali var. pyri & NXLW96 & Pyrus spp. & Lingwu, Ningxia & 2005 & JN662368 \\
\hline V. mali var. pyri & SXBXp157 & Pyrus spp. & Binxian, Shaanxi & 2005 & JN662369 \\
\hline V. mali var. pyri & GSZYpm160 & Pyrus spp. & Zhangye, Gansu & 2005 & JN662370 \\
\hline V. mali var. pyri & NXLWp161 & Pyrus spp. & Lingwu, Ningxia & 2005 & JN662371 \\
\hline V. mali var. pyri & SXWBp162 & Pyrus spp. & Wubu, Shaanxi & 2005 & JN662372 \\
\hline$V$. malicola & $03-1-2$ & M. domestica & Qishan, Shaanxi & 2003 & JN545839 \\
\hline$V$. persoonii & $32-2 w$ & M. domestica & Yangling, Shaanxi & 2003 & JN584644 \\
\hline V. sordida & YSFL & Populus tomentosa & Yangling, Shaanxi & 2009 & JN545841 \\
\hline Valsa sp. & LSFL & Salix babylonica & Yangling, Shaanxi & 2009 & JN575604 \\
\hline Alternaria sp. & LGB & M. domestica & Yangling, Shaanxi & 2009 & JN575601 \\
\hline Botryosphaeria dothidea & PGLW & M. domestica & Yangling, Shaanxi & 2009 & JN545840 \\
\hline Cladosporium $\mathrm{sp}$. & PZM & M. domestica & Yangling, Shaanxi & 2009 & JN575603 \\
\hline Fusarium sp. & LDJ & M. domestica & Yangling, Shaanxi & 2009 & JN575600 \\
\hline Penicillium digitatum & QMPdi & M. domestica & Yangling, Shaanxi & 2009 & JN575602 \\
\hline Phoma glomerata & JDMgl & M. domestica & Yangling, Shaanxi & 2009 & JN575598 \\
\hline Phoma sp. & JDMsp & M. domestica & Yangling, Shaanxi & 2009 & JN575599 \\
\hline Puccinia striformis f. sp. tritici & TZ33 & Triticum aestivum & Yangling, Shaanxi & 2008 & JN575605 \\
\hline
\end{tabular}


Sequencing of nested PCR detection products. The DNA extractions from pure culture, symptomless bark tissues, naturally infected canker tissues, and artificially inoculated apple twig tissues were used as templates in the nested PCR, after which the PCR products were purified using an agarose Gel DNA Extraction Kit (Generay). The purified PCR products were directly sequenced independently along both strands with species-specific primers $\mathrm{VmF}$ and $\mathrm{VmR}$, and then the sequences were aligned using the DNAMAN 6.0 software package (Lynnon Biosoft).

Evaluation of two methods for detecting $V$. mali var. mali in apple twigs. All samples used in this experiment were derived either from symptomless tissues or infected tissues with visible
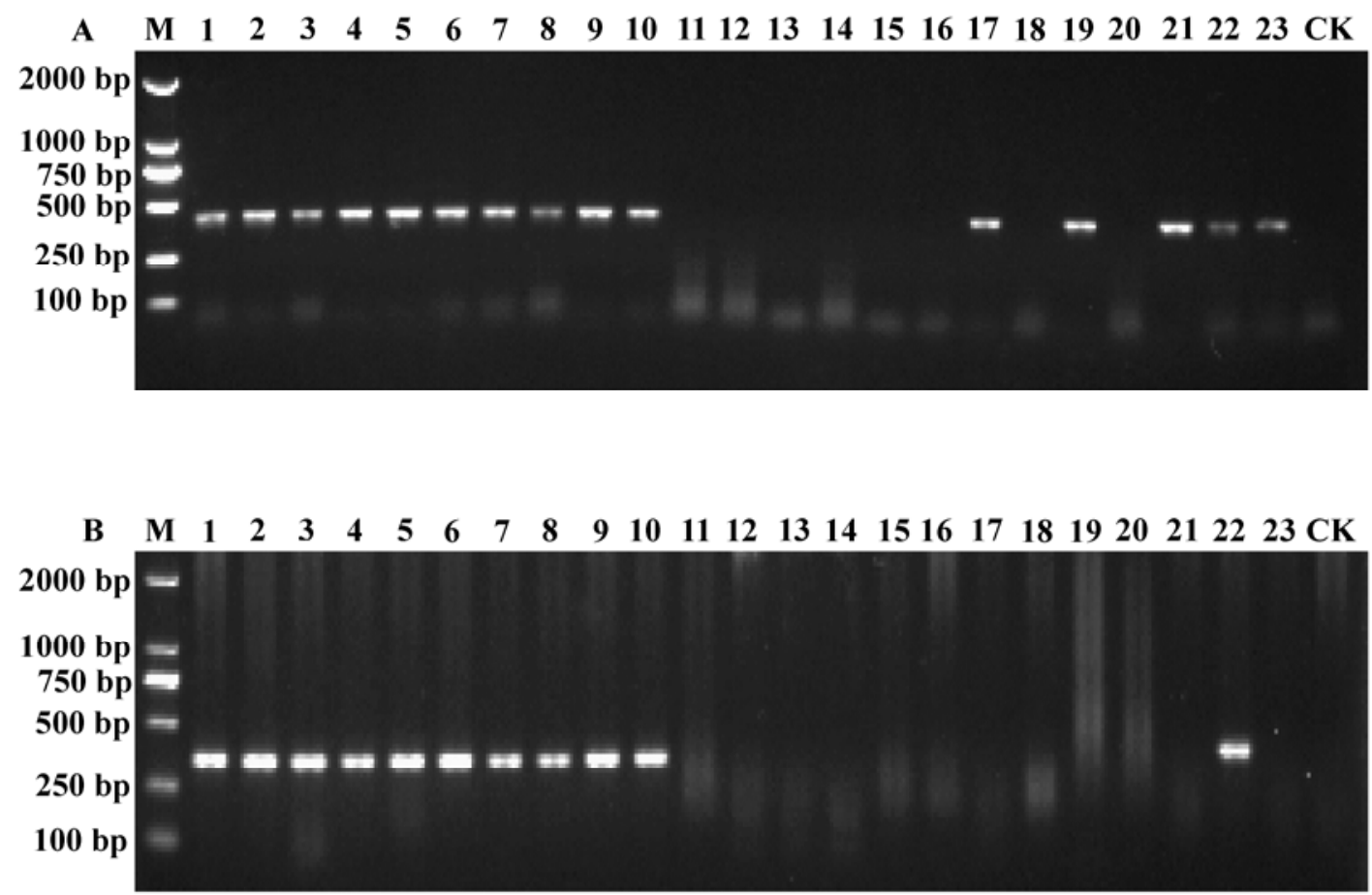

Fig. 1. Specificity of genus-specific and species-specific primers for Valsa mali var. mali in the $\mathbf{A}$, first and $\mathbf{B}$, second run of nested polymerase chain reaction, respectively using DNA from $V$. mali var. mali isolates and other species. Lanes 1-10, V. mali var. mali isolates SXMX02, 03-8-1, SXFF43, \$XYC46, SXPC69, GSLZ86, NXLW92, SDQX118, HBBD10, and HNXX47, respectively; lanes 11-20, Cladosporium sp., Penicillium digitatum, Phoma glomerata, Phoma sp., Fusarium sp., Puccinia strifformis f. sp. tritici, Valsa sp., Alternaria sp., V. sordida, and Botryosphaeria dothidea, respectively; lanes 21-23, DNA from V. malicola isolates 03-1-2, V. mali var. mali isolate $\$ X Y C 46$, and V. persoonii isolate 32-2w, respectively; V. mali var. mali isolate \$XYC46 was used as positive control; CK, negative control (no DNA template); M, DL-2000 DNA ladder.
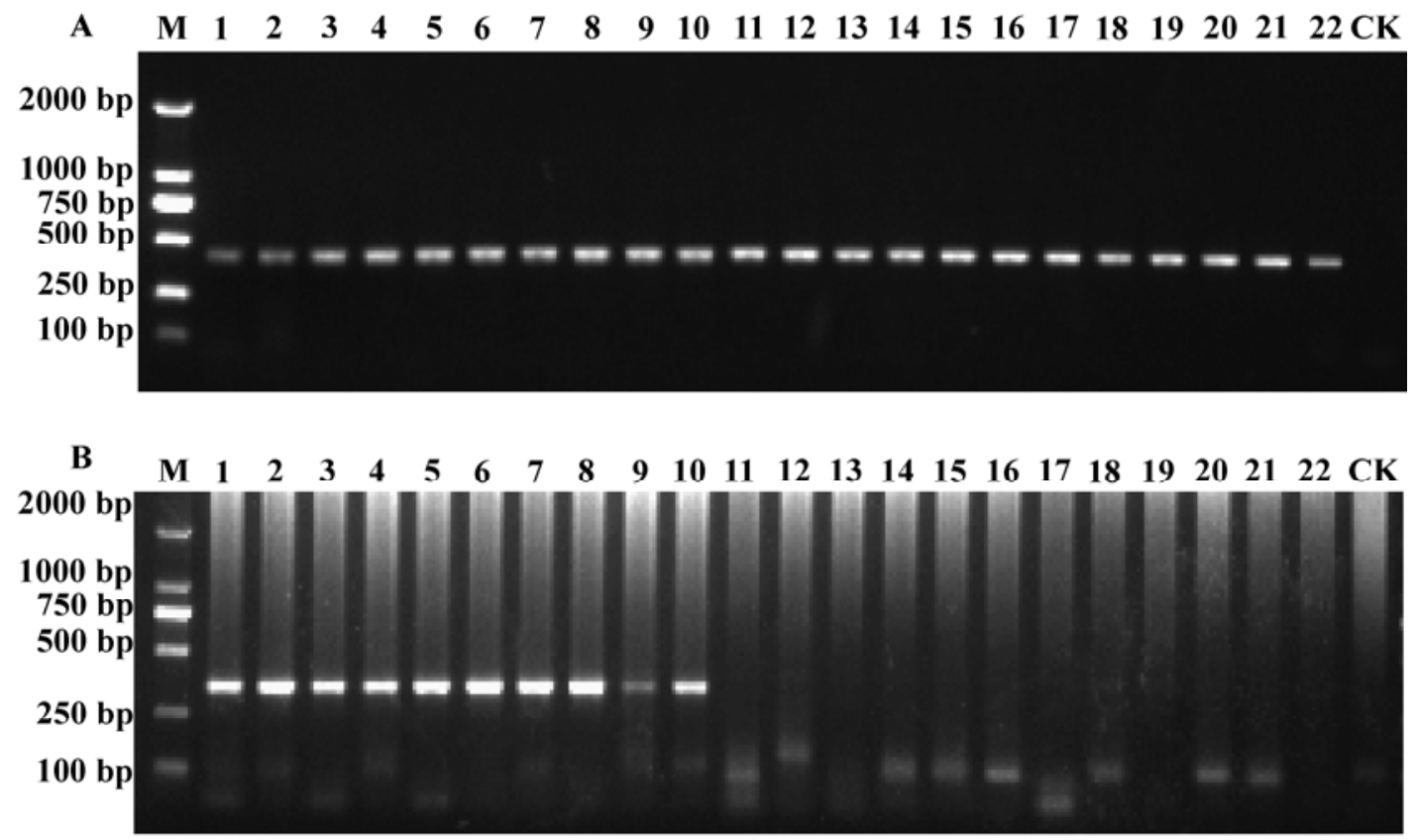

Fig. 2. Amplification products of the $\mathbf{A}$, first and $\mathbf{B}$, second run of nested polymerase chain reaction using the genomic DNA of Valsa mali var. mali and $V$. mali var. pyri, respectively. Lanes 1-10, V. mali var. mali isolates SXMX02, 03-8-1, SXFF43, \$XYC46, SXPC69, GSLZ86, NXLW92, SDQX118, HBBD10, and HNXX47, respectively, isolated from apple; lanes 11-15, V. mali var. pyri isolates 03-14-1, SXYL126, SXYL134, SXYL135, and GSZY113, respectively, isolated from apple; lanes 16-20, V. mali var. pyri isolates NXLW96, SXBXp157, GSZYpm160, NXLWp161, and SXWBp162, respectively, isolated from pear; lanes 21 and 22, DNA of V. malicola isolate 03-1-2 and V. persoonii isolate 32-2w, respectively; CK, negative control (no DNA template); M, DL-2000 DNA ladder. 
symptoms. The infected samples included twigs with canker symptoms showing visible pycnidia or soaked periderm tissue. The symptomless samples were the twigs showing no visible cankers. All samples were randomly collected from different apple orchards and washed with tap water. Then, a $1.5-\mathrm{cm}^{2}$ sample was cut in half. One half was used to isolate the fungal species present in pure culture while the other half was cut into small pieces and ground to a fine powder for DNA extraction. The DNA samples isolated were used as a template for the first round of nested PCR amplification.

Detection of $V$. mali var. mali from different apple tissues by nested PCR. DNA was extracted from different apple tissues as described above. The nested PCR assay using the genus-specific primers $\mathrm{VF}+\mathrm{VR}$ and species-specific primers $\mathrm{VmF}+\mathrm{VmR}$ was conducted as described above. The presence of $V$. mali var. mali in different tissues of apple trees was analyzed statistically using the SNK test ( $Q$ test) (SAS 8.0; SAS institute Inc.).

\section{Results}

Primer design. Using the ITS1 and ITS4 primers, we were able to detect an amplified DNA fragment of $560 \mathrm{bp}$ from $V$. mali var. mali. This DNA fragment was subjected to sequence analysis. Based on the rDNA-ITS conserved sequence of the Valsa genus, a pair of genus-specific primers designated as VF (5'-GTT GCC TCG GCG CTG GCT-3') and VR (5'-GCG AGG GTT TTA CTA CTG C-3') was designed. Using this pair of primers in the nested PCR assay, a DNA fragment of approximately $400 \mathrm{bp}$ was detected from $\mathrm{V}$. mali var. mali in the first round of amplification (Figs. 1A and 2A). Based on the rDNA-ITS idiosyncratic sequence of $V$. mali var. mali, a pair of species-specific primers, VmF (5'-GAG TAC TCC CTC CCG CTC CG- $\left.3^{\prime}\right)$ and VmR (5'-TTA ATT AAG GGG CGG CCT CA$\left.3^{\prime}\right)$, was designed. Using this pair of primers in the second round
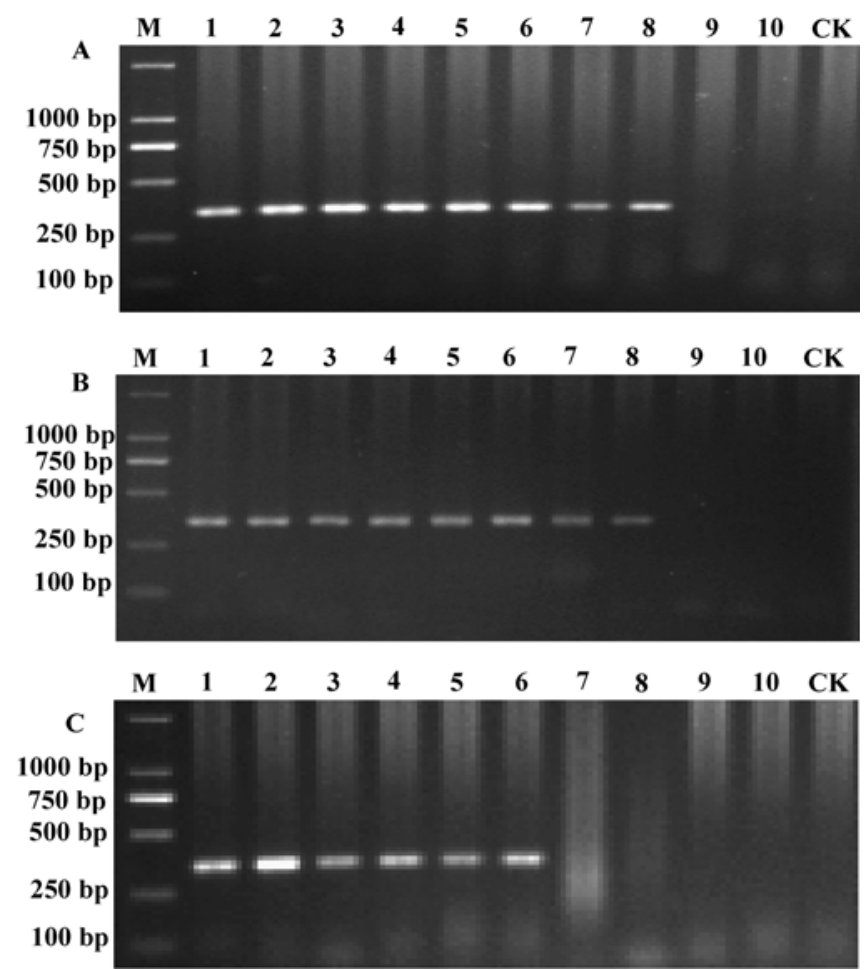

Fig. 3. Sensitivity of nested polymerase chain reaction with species-specific primers $\mathrm{VmF}$ and $\mathrm{VmR}$ for detection of Valsa mali var. mali. A, DNA extracted from a pure culture of $V$. mali var. mali isolate 03-8-1 isolated from apple in Shaanxi province. Lanes 1-10, DNA at $400 \mathrm{ng}, 40 \mathrm{ng}, 4 \mathrm{ng}, 1 \mathrm{ng}, 100 \mathrm{pg}, 10 \mathrm{pg}, 1 \mathrm{pg}, 100 \mathrm{fg}, 10 \mathrm{fg}$, and $1 \mathrm{fg} / \mu \mathrm{l}$, respectively. B, DNA extracted from apple bark tissue with visible symptoms. Lanes $1-10$, The same concentrations as A. C, DNA extracted from symptomless apple bark tissue. Lanes 1-10, DNA at $300 \mathrm{ng}, 30 \mathrm{ng}, 3 \mathrm{ng}, 1 \mathrm{ng}, 100$ $\mathrm{pg}, 10 \mathrm{pg}, 1 \mathrm{pg}, 100 \mathrm{fg}, 10 \mathrm{fg}$, and $1 \mathrm{fg} / \mu \mathrm{l}$, respectively. CK, negative control (no DNA template); M, DL-2000 DNA ladder. of amplification, a DNA fragment of 348 bp was specifically detected from $V$. mali var. mali.

Specificity of the assay. The specificity of this assay using the species-specific primers designed for detecting $V$. mali var. mali was evaluated by testing various isolates of Valsa and other fungal species which served as negative controls (Table 1). Using these primers (VmF and -R), the nested PCR was able to amplify a DNA fragment with an expected size of $348 \mathrm{bp}$ when DNA from all $V$. mali var. mali isolates was used as a template but was unable to do so when DNA from isolates of other fungal species and V. mali var. pyri was used (Figs. 1B and 2B). Thus, this nested PCR assay could be applied specifically for the detection of $V$. mali var. mali present in apple trees.

Sensitivity of the assay. The sensitivity of the assay was tested by using the DNA extracted from a pure culture of $V$. mali var. mali after a serial DNA dilution from $400 \mathrm{ng} / \mu \mathrm{l}$ to $1 \mathrm{fg} / \mu \mathrm{l}$. The results of this study revealed that this assay was able to detect a 348-bp DNA fragment when the tested DNA concentrations were in the range of $100 \mathrm{fg} / \mu \mathrm{l}$ to $400 \mathrm{ng} / \mu \mathrm{l}$. Thus, when the conserved primers (VF and VR) were used in the first round of amplification and species-specific primers ( $\mathrm{VmF}$ and $\mathrm{VmR})$ were used in the second round of amplification in the nested PCR assay, V. mali var. mali could be detected in mycelial samples at DNA concentrations as low as 100 fg/ $\mu \mathrm{l}$ (Fig. 3A). When DNA extracts from apple bark tissues with visible symptoms were used as a template in the nested PCR, the same result was obtained (Fig. 3B). However, when DNA extracts from symptomless apple bark tissue were used, the lowest detectable concentration was $10 \mathrm{pg} / \mu \mathrm{l}$ (Fig. 3C). These data show that the assay is highly sensitive for detection of $V$. mali var. mali in different types of samples.

Nested PCR detection in different apple samples and sequencing of PCR products. The nested PCR was used to detect $V$. mali var. mali in artificially inoculated apple twigs, pure cultures, naturally infected canker tissues, and symptomless bark tissues, after which the PCR products were sequenced. The canker symptoms appeared on apple twigs 20 days after artificial inoculation. There were no obvious canker symptoms in the controls inoculated with PDA plugs. The DNA was extracted from the infected tissues, and an expected PCR product with a size of $348 \mathrm{bp}$ was observed when the DNA isolated from the infected tissues was used as a template in the nested PCR assay. Similarly, when DNA isolated from pure culture, symptomless bark tissues, and naturally infected canker tissues was used as a template, a PCR product with the same size was observed (Fig. 4). Sequencing results showed that the detected PCR products from these four kinds of samples had the same sequence as the PCR detection products from mycelium (Fig. 5). Therefore, they were considered to be the same species.

Validation of the assay by fungal isolation. To validate the nested PCR assay results, the conventional fungal isolation method was employed. In all, 40 naturally infected samples with symptoms and 34 samples without symptoms were tested. A positive PCR signal (i.e., a 348-bp PCR product) was observed in all tested natu-

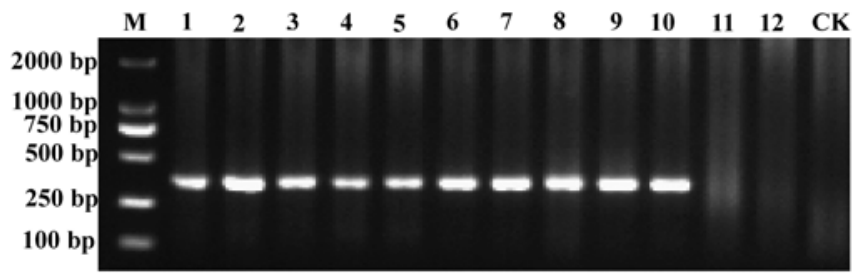

Fig. 4. Detection of Valsa mali var. mali in naturally infected canker tissue, artificially inoculated twig tissue, and symptomless bark tissue by the nested polymerase chain reaction with species-specific primers. Lanes 1-3, DNA samples from naturally infected canker tissue; lanes 4-6, DNA samples from canker tissue on artificially inoculated twigs; lanes 7-9, DNA samples from symptomless bark tissue; lanes 10-12, DNA of V. mali var. mali isolate 03-3-1, V. persoonii isolate 32$2 \mathrm{w}$, and $V$. malicola isolate $03-1-2$, respectively, from pure cultures; $V$. mali var. mali isolate 03-3-1 served as positive control; M, DS-2000 DNA ladder; CK, negative control (no DNA template). 
rally infected samples. By the fungal isolation method, the pathogen was also detected in these samples. The detection rate of the nested PCR and fungal isolation for naturally infected samples was $100 \%$ in both cases. Among the 34 samples without obvious symptoms, 22 samples yielded a positive PCR signal while the remaining 12 samples did not. The detection rate of the nested PCR for symptomless samples was $64.7 \%$ (22/34). Subsequently, we were able to isolate $V$. mali var. mali from seven of the symptomless samples. Meanwhile, the presence of $V$. mali var. mali in these seven samples was also confirmed by the nested PCR. Moreover, the seven samples were included in the 22 samples that yielded a positive PCR signal. There were 15 samples in which the presence of the pathogen was detected by the nested PCR assay but failed by fungal isolation. Therefore, the detection rate of fungal isolation for symptomless samples was $20.6 \%$ (7/34), which was much lower than the detection rate of $64.7 \%$ by nested PCR. There were no samples from which the fungi could be isolated but failed to be detected by the nested PCR. These data indicate that the nested PCR is more sensitive and reliable than fungal isolation.

Comparison of $\boldsymbol{V}$. mali var. mali infection in symptomless apple tissues in orchards with different diseased tree incidence. In this study, the presence of $V$. mali var. mali in symptomless apple tissues (terminal buds, internodes, and bud scale scars) was evaluated by nested PCR. In three orchards where the diseased tree incidence was $80 \%$ in each, 179 symptomless samples in all from different tissues were collected and analyzed by the PCR assay, and V. mali var. mali was detected in 150 of the samples. Thus, the incidence of $V$. mali var. mali in symptomless apple tissues in these orchards was $83 \%$, similar to the diseased tree incidence. Yet, in another three orchards where the diseased tree incidence was 28 , 40 , and $36 \%$, respectively (on average, $34.7 \%$ ), 177 symptomless samples in total were collected and analyzed by the PCR assay, and the presence of $V$. mali var. mali was detected in 97(55\%) of the samples. The orchards were divided into two types according to the diseased tree incidence: type I was composed of orchards with a high diseased tree incidence $(80 \%)$ and type II consisted of orchards with a moderate diseased tree incidence $(<40 \%)$. The $Q$ test result showed that the incidence of $V$. mali var. mali in various plant tissues in high-disease-incidence orchards was significantly different from those with moderate disease incidence $(F=10.61, P$ $=0.0069$ ). Furthermore, our results showed that $V$. mali var. mali was present in all tested symptomless tissues on apple trees. The statistical analysis also indicated that the incidence of $V$. mali var. mali in different tissues was significantly different $(F=7.11, P=$ 0.0092). V. mali var. mali was detected in $89 \%$ of tested terminal bud samples on average. In internodes, the incidence was $71 \%$ on average, and the detection rate was $48 \%$ in bud scale scars (Table 2).

\section{Discussion}

In this study, a PCR-based assay for detecting the pathogen causing Valsa canker (namely, V. mali var. mali) in apple trees was developed. This PCR assay could be used for rapid and accurate detection of the causal agent $V$. mali var. mali in different tissues with or without visible canker symptoms. Moreover, compared with the traditional fungal isolation method, the nested PCR assay is more sensitive in detecting $V$. mali var. mali from symptomless tissues. Therefore, the V. mali var. mali incidence in orchards or in different tissues can be monitored much earlier by the PCR assay, at an early stage of infection before symptoms appear. It was very critical for effectively controlling disease at this early stage of infection by protective fungicides. Otherwise, it is very difficult to control disease by inhibiting pathogen development in the bark tissues because the mycelia have been invading in the phloem and even deeper tissues. Our assay could provide an exact prediction of the disease in the orchard to help growers take control measures as early as possible. In addition, it is easy for the fungicides to enter the outer layers of the bark to inhibit mycelia growth. Moreover, by

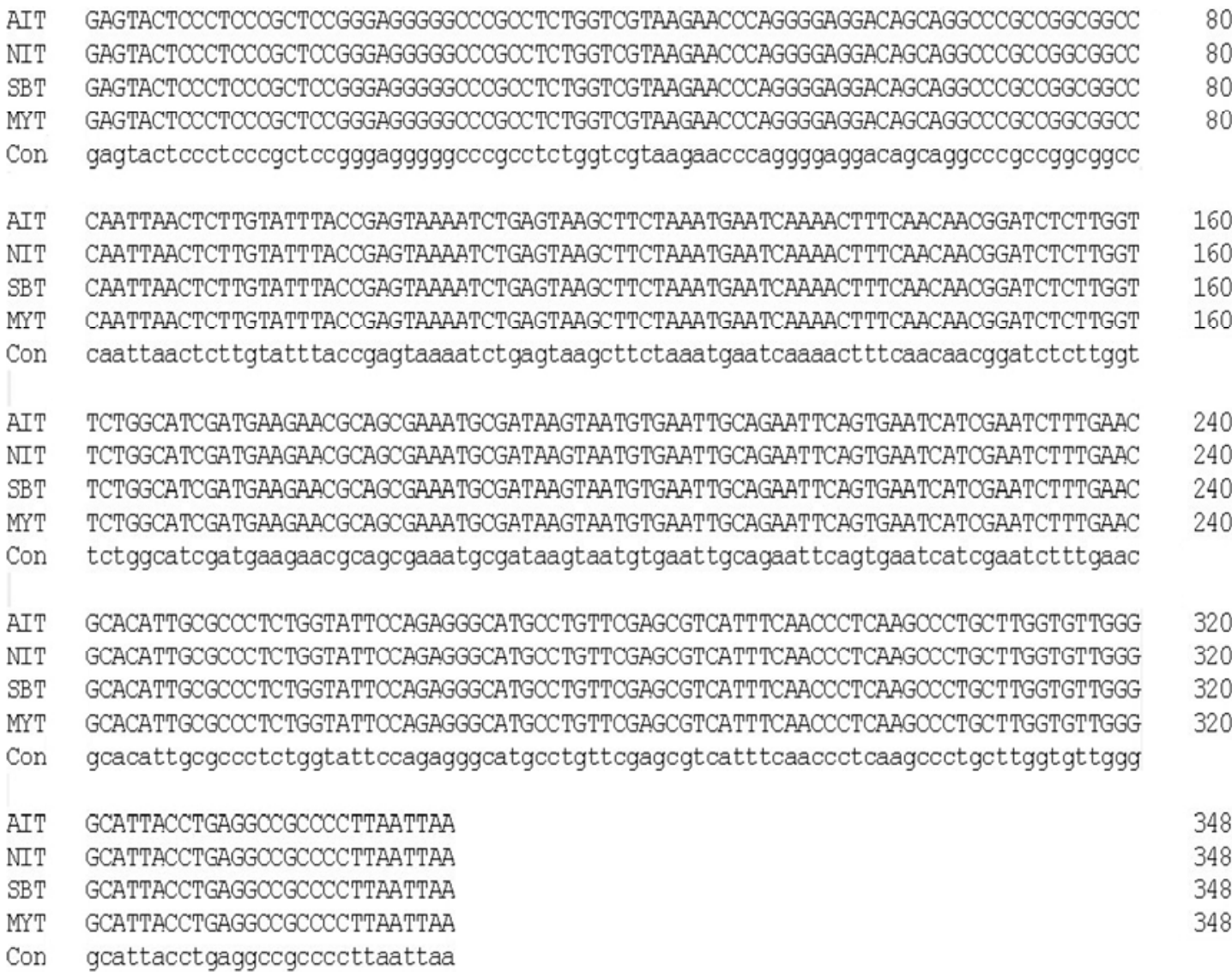

Fig. 5. Multiple sequence alignment of the nested polymerase chain reaction products from naturally infected canker tissue (NIT), artificially inoculated twigs tissue (AIT), symptomless bark tissue (SBT), and fungal mycelium (MYT) with species-specific primers VmF and VmR. Con, consensus sequence. 
the detection of $V$. mali var. mali incidence in different tissues, the places where the pathogen survived can be found, which paves the way for much better understanding of the rules of disease development.

To develop a reliable and sensitive PCR assay, it was critically important to obtain genomic DNA samples of high quality for use as template for amplification. There are many factors that may hinder the isolation of high-quality fungal DNA from plant tissues suitable for PCR, such as sampling sites on twigs, sample processing, and presence of substances in plant tissue interfering with PCR (9). In our DNA extraction procedure, we added PVP and $\beta$ mercaptoethanol to prevent DNA degradation and also a larger amount of sodium acetate to facilitate DNA precipitation. We believe that these measures might have contributed to the isolation of high-quality genomic DNA samples for the assay. For efficient amplification, we believe that using sufficiently diluted DNA samples is critical. However, this could reduce sensitivity. In this study, we used the original DNA preparations without further dilution and obtained a strong and expected DNA fragment by the nested PCR, indicating that the assay developed in this study is sensitive and reproducible.

A reliable PCR assay also depends on the design and use of the primers specific to the intended target pathogens (8). In this study, we designed the species-specific primers according to the idiosyncratic ITS sequences of three $V$. mali var. mali isolates from different regions. Although variation was discovered in the ITS region of $V$. mali isolates, two varieties, V. mali var. mali and V. mali var. pyri, were recognized by seven nucleotide substitution sites in the ITS sequences. V. mali var. mali was more aggression than $V$. mali var. pyri on apple (18). Additionally, we found that V. mali var. mali was dominant, comprising $99.2 \%$ (729/735) of the isolates obtained from apple trees. These were also the reasons why we designed primers to detect $V$. mali var. mali rather than $V$. mali var. pyri. When we used these primers to test closely related fungal species, the primer pair $\mathrm{VmF}$ and $-\mathrm{R}$ amplified a DNA fragment with a size of $348 \mathrm{bp}$ from $\mathrm{V}$. mali var. mali isolates but failed to yield any obvious fragments from other fungal species tested. Furthermore, when DNA extracts from V. mali var. mali and V. mali var. pyri were used as templates in the nested PCR assay, the expected 348-bp DNA fragment was generated only in $V$. mali var. mali isolates. Thus, these results demonstrate that the primers $\mathrm{VmF}$ and $-\mathrm{R}$ used in this study are specific to the target pathogen. Whereas the one-step PCR can detect DNA concentrations as low as $40 \mathrm{ng} / \mu \mathrm{l}$, the nested PCR assay can detect $100 \mathrm{fg} / \mu \mathrm{l}$ when DNA extracts from mycelium and symptomatic apple bark are used as templates. When DNA extracts from symptomless apple bark tissue were used as templates, the lowest detectable limit was DNA at $10 \mathrm{pg} / \mu \mathrm{l}$; however, one-step regular PCR cannot detect pathogen in these samples at all (Fig. 6). Thus, the nested-PCR assay can be used to detect a latent pathogen in extremely low quantities within apple tree bark.
Subsequently, in our assay validation study, all the samples from which the pathogens were successfully isolated yielded a positive PCR signal, thereby confirming that the nested PCR assay is a sensitive and reliable detection method. In some cases, where fungi were not isolated from the samples but were detected by the nested PCR assay, this may be due to the lower sensitivity of the conventional isolation method. On the other hand, it is possible that the DNA extracted from dead V. mali var. mali cells still can be amplified using the nested PCR assay. Isolation is generally less efficient, because small hyphae may not survive the isolation process or are just not present in the small sections plated. These might have explained why, in some cases, the pathogen could be detected by the nested PCR assay but subsequently failed to be isolated by
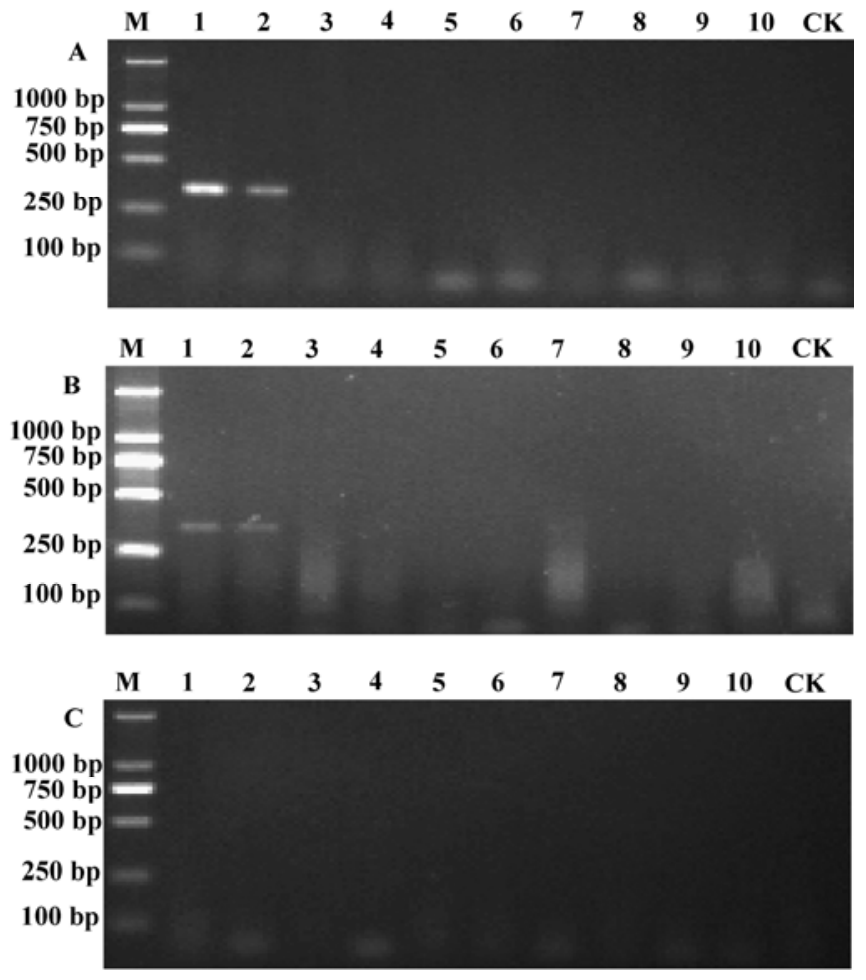

Fig. 6. Sensitivity of one-step polymerase chain reaction with species-specific primers $\mathrm{VmF}$ and $\mathrm{VmR}$ for detection of Valsa mali var. mali. A, DNA extracted from a pure culture of $V$. mali var. mali isolate 03-8-1 isolated from apple in Shaanxi province. Lanes 1-10, DNA at $400 \mathrm{ng}, 40 \mathrm{ng}, 4 \mathrm{ng}, 1 \mathrm{ng}, 100 \mathrm{pg}, 10 \mathrm{pg}, 1 \mathrm{pg}, 100$ $\mathrm{fg}, 10 \mathrm{fg}$, and $1 \mathrm{fg} / \mathrm{\mu l}$, respectively. B, DNA extracted from apple bark tissue with visible symptoms. Lanes 1-10, The same concentrations as A. C, DNA extracted from symptomless apple bark tissue. Lanes 1-10, DNA at $300 \mathrm{ng}, 30 \mathrm{ng}, 3 \mathrm{ng}, 1$ $\mathrm{ng}, 100 \mathrm{pg}, 10 \mathrm{pg}, 1 \mathrm{pg}, 100 \mathrm{fg}, 10 \mathrm{fg}$, and $1 \mathrm{fg} / \mu \mathrm{l}$, respectively; CK, negative control (no DNA template); M, DL-2000 DNA ladder.

Table 2. Nested polymerase chain reaction (PCR) detection of Valsa mali var. mali incidence in different tissues of apple trees obtained from the orchards with different diseased tree incidence in Yangling, Shaanxi province in 2011

\begin{tabular}{lcccc}
\hline & & & Incidence in tissue (\%) $^{\mathbf{x}}$ \\
\cline { 3 - 5 } Orchard type, number & Diseased tree incidence $(\%)^{\mathbf{y}}$ & Terminal bud $^{\mathbf{z}}$ & Internode $^{\text {Bud scale scar }}$ \\
\hline I & 80 & 100 & 100 & 40 \\
1 & 80 & 100 & 100 & 85 \\
2 & 80 & 80 & 90 & 60 \\
3 & 28 & 75 & 60 & 5 \\
II & 40 & 100 & 60 & 55 \\
4 & 36 & 80 & 15 & 41 \\
5 & $\ldots$ & $89 \mathrm{a}$ & $71 \mathrm{ab}$ & $48 \mathrm{~b}$ \\
6 & & & \\
Average incidence & & & \\
\hline
\end{tabular}

\footnotetext{
${ }^{\mathrm{x}}$ Lowercase letters represent horizontal comparison: shared letters indicate no significant difference at $P=0.05$ using the SNK test $(Q$ test).

${ }^{y}$ Incidence of diseased trees in each orchard was calculated by evaluation of 25 trees.

${ }^{\mathrm{z}}$ In each orchard, five trees with typical symptoms were randomly selected and four 1-year-old symptomless twigs in four directions were cut from each tree; thus, 20 samples were tested by the nested PCR assay.
} 
the isolation methods. Admittedly, because of the specificity of species-specific primers in the nested PCR, we are not sure, by the nested PCR, whether V. mali var. pyri exist in the naturally infected samples and some symptomless samples from which the expected 348-bp DNA fragment was not amplified. However, the pathogen was not obtained by the fungal isolation method either and, therefore, the test appears reliable.

According to the detection results, we now know that $V$. mali var. mali incidence in symptomless tissues was over 50\% (55\%) in the orchards in Shaanxi Province. The results suggest that $V$. mali var. mali can invade and colonize many apple tree tissues. We infer that this pathogenic fungus could cause latent infection for a long time and survive in any weak and dead tissues on the apple trees. The similar pathogen Cytospora chrysosperma (Pers.) Fr. also might cause latent infection, as suggested by Christensen et al. (5). On the basis of this finding, we advised the growers to change their disease control strategy from treatments after symptoms appear to prevention measures prior to the appearance of visible cankers. Our results suggest that the growers could control disease by taking different measures to reduce inoculum concentrations and latent infections; for example, spraying fungicides over the whole trees and on areas on the trunks or scaffold limbs where cankers have been surgically removed, and pruning the weak, dead twigs. Moreover, the infected twigs and bark tissues with symptoms were promptly removed and deeply buried or burned rather than piled up in the orchards. A proper utilization of fertilization and irrigation was necessary to improve the vigor of trees to aid in reducing the infection. The results of this study have improved the understanding of inoculum sources of $V$. mali var. mali in apple orchards in western China and suggest avenues for improved management of the disease.

However, the nested PCR assay was based on the fungal genomic DNA which might be extracted from living and dead fungal cells. Therefore, for better understanding and more accurate detection of the fungus infection, real-time reverse-transcription PCR should have been used to confirm viability of fungal cells.

Meanwhile, due to the fact that these studies were conducted using samples collected during the harvest season, it is possible that the distribution of this pathogen in different tissues may vary in different seasons. For example, the Cytospora pathogens on many trees could attack the hosts as facultative wound parasites when the vigor of the hosts had declined (2). Many factors can cause poor vigor of the hosts, such as drought, freezing, winter injury, or severe pruning. The vigor of the apple trees might vary in different seasons. Therefore, it is important to conduct these types of studies using samples collected during different growing periods in order to have a better understanding of the epidemic development of Valsa canker in apple trees.

In summary, the nested PCR assay developed in this study is highly sensitive and specific for detecting the presence of $V$. mali var. mali in apple trees as compared with the traditional culture isolation method. This nested PCR assay is suitable for detecting the fungal pathogen present in tissues with and without symptoms. This method could also be used to predict and monitor the presence of this pathogen at early stages of disease development, which is critical to gain insight into the epidemiology of the disease, thereby aiding the development of effective strategies for controlling the disease.

\section{Acknowledgments}

This study was supported by the National Natural Science Foundation of China (numbers 30771396 and 31171796), the Program for Agriculture (nyhyzx201203034-03), and the 111 Project (B07049). We thank Y. Duan and L. Deng for their excellent technical assistance, J. Liu and L. Wang for their tremendous efforts in sample collection and pathogen isolation, P. Goodwin at the University of Guelph for comments on this manuscript prior to submission, $\mathrm{H}$. Buchenauer and G. Zhao for critically reviewing the manuscript, and the reviewers whose comments and suggestions helped to improve our manuscript.

\section{Literature Cited}

1. Abe, K., Kotoda, N., Kato, H., and Soejima, J. 2007. Resistance sources to Valsa canker (Valsa ceratosperma) in a germplasm collection of diverse Malus species. Plant Breed. 126:449-453.

2. Adam, G. C., Roux, J., and Wingfield, M. J. 2006. Cytospora species (Ascomycota, Diaporthales, Valsaceae): introduced and native pathogens of trees in South Africa. Australas. Plant Pathol. 35:521-548.

3. Catal, M., Jordan, S. A., Butterworth, S. C., and Schilder, A. M. C. 2007. Detection of Eutypa lata and Eutypella vitis in grapevine by nested multiplex polymerase chain reaction. Phytopathology 97:737-747.

4. Chen, C., Li, M. N., Shi, X. Q., and Wang, J. Y. 1987. Studies on the infection period of Valsa mali Miyabe et Yamada, the causal agent of apple tree canker. Acta Phytopathol. Sin. 17:65-68.

5. Christensen, C. M. 1940. Studies on the biology of Valsa sordida and Cytospora chrysosperma. Phytopathology 30:459-475.

6. Flowers, J., Hartman, J., and Vaillancourt, L. 2003. Detection of latent Sphaeropsis sapinea infections in Austrian pine tissues using nestedpolymerase chain reaction. Phytopathology 93:1471-1477.

7. Lee, S. B., Milgroom, M. G., and Taylor, J. W. 1988. A rapid, high yield mini-prep method for isolation of total genomic DNA from fungi. Fungal Genet. Newsl. 35:23-24

8. Ma, Z., Luo, Y., and Michailides T. J. 2003. Nested PCR assays for detection of Monilinia fructicola in stone fruit orchards and Botryosphaeria dothidea from Pistachios in California. J. Phytopathol. 151:312-322.

9. Malvick, D. K., and Grunden, E. 2005. Isolation of fungal DNA from plant tissues and removal of DNA amplification inhibitors. Mol. Ecol. Notes 5:958-960.

10. Martin, R. R., James, D., and Lévesque, C. A. 2000. Impacts of molecular diagnostic technologies on plant disease management. Annu. Rev. Phytopathol. 38:207-239.

11. Mercado-Blanco, J., Rodríguez-Jurado, D., Parrilla-Araujo, S., and Jiménez-Díaz, R. M. 2003. Simultaneous detection of the defoliating and nondefoliating Verticillium dahliae pathotypes in infected olive plants by duplex, nested polymerase chain reaction. Plant Dis. 87:1487-1494.

12. Piškur, B., Ogris, N., and Jurc, D. 2007. Species-specific primers for $E u$ typella parasitica, the causal agent of Eutypella canker of maple. Plant Dis 91:1579-1584.

13. Sakuma, T. 1990. Valsa canker. Pages 39-40 in: Compendium of Apple and Pear Diseases. A. L. Jones and H. S. Aldwinckle, eds. American Phytopathological Society, St. Paul, MN.

14. Suzaki, K. 2008. Population structure of Valsa ceratosperma, causal fungus of Valsa canker, in apple and pear orchards. J. Gen. Plant Pathol. 74:128132.

15. Uhm, J. Y., and Sohn, H. R. 1995. Control of apple Valsa canker by localized spraying with neoasozin solution, an arsenic fungicide. Korean J. Plant Pathol. 11:9-16.

16. Wang, L., Zang, R., Huang, L. L., Xie, F. Q., and Gao, X. N. 2005. The investigation of apple tree Valsa canker in Guanzhong region of Shaanxi province. J. NW Sci.-Tech. Univ. Agric. For. (Nat. Sci. Ed.) 33(Suppl.):98100.

17. Wang, X. J., Zheng W. M., Buchenauer, H., Zhao, J., Han, Q. M., Huang, L. L., and Kang, Z. S. 2008. The development of a PCR-based method for detecting Puccinia striiformis latent infections in wheat leaves. Eur. J. Plant Pathol. 120:241-247.

18. Wang, X. L., Wei, J. L., Huang, L. L., and Kang, Z. S. 2011. Re-evaluation of pathogens causing Valsa canker on apple in China. Mycologia 103:317324.

19. Wei, J. L., Huang, L. L., Gao, Z. P., Ke, X. W., and Kang, Z. S. 2010. Laboratory evaluation methods of apple tree Valsa canker disease caused by Valsa ceratosperma sensu Kobayashi. Acta Phytopathol. Sin. 40:14-20.

20. White, T. J., Bruns, T., Lee, S., and Taylor, J. 1990. Amplification and direct sequencing of fungal ribosomal RNA genes for phylogenetics. Pages 315322 in: A Guide to Methods and Applications. Academic Press, San Diego, CA.

21. Zang, R., Wang, X. L., Huang, L. L., and Kang, Z. S. 2007. Biological characteristics and pathogenicity of different isolates of Cytospora spp. isolated from apple trees in Shaanxi province. Acta Phytopathol. Sin. 37:343351.

22. Zhang, Y. P., Uyemoto. J. K., and Kirkpatrick, B. C. 1998. A small-scale procedure for extracting nucleic acids from woody plants infected with various phytopathogens for PCR assay. J. Virol. Methods 71:45-50. 